\title{
Factors Affecting Employee Turnover Intention among Non- Managerial Employees in Selected Financial Companies in Colombo District
}

\author{
H. M. M. A. Wijebandara ${ }^{1}$, G. S. Malalage ${ }^{2}$ and W. R. P. K. Fernando ${ }^{3}$ \\ ${ }^{1}$ SIOT Service (Pvt) Limited, Sri Lanka \\ ${ }^{2,3}$ Department of Commerce and Financial Management, Faculty of Commerce and \\ Management Stduies, University of Kelaniya, Sri Lanka
}

\begin{abstract}
Human capital is a dominant element of today's' business world. Nowadays, Employee turnover is one of those who are one of the problematic issues in business. The intention to leave has received tremendous attention and significance from top management, human resource professionals and other industrial psychologists. It has proven to be one of the most costly and difficult human resource challenges faced globally by different organizations. The main purpose of this research was to discover the real causes behind the turnover and its harmful effects on the productivity of many industries, especially financial companies. The study had studied many sources related to the non-banking financial company sector in Sri Lanka and observed the causes for turnover. This study aimed to discover the reasons for turnover and factors affecting turnover intention among non-managerial employees. Using simple random sampling technique, the sample of the study was 150 non-managerial employees who are working in those financial companies located in Colombo district. Sample collected represent $50 \%$ of the total population. Findings showed that the employee turnover intention has a significant relationship with the variables of job satisfaction \& supervisor support, but it had an insignificant relationship with salary and the other benefits and organizational culture. Whereas, the major contributor to turnover intention was job satisfaction.
\end{abstract}

Keywords: Turnover Intention, Salary Benefit, Organizational Culture, Job Satisfaction, Supervisor Support

\section{Introduction}

Turnover intention is a major issue in the field of human resource management. It depends on employee personal reasons. Further, the intention to leave a job is defined as an 'individual's expected chance'. They are quitting the organization permanently at some point soon. Moreover, turnover occurs when the employees have an alternative best opportunity. While involuntary turnover intention occurs when an organization is not satisfied with employee performance and makes the decision to fire him (Tsai $\& \mathrm{Wu}, 2010)$. Turnover intention can be either voluntary or involuntary. In voluntary turnover, employee leaves the organization willingly. In many countries,' employee turnover gives sleepless nights to human resource managers. A widespread belief in many countries is that due to a lack of workforce employees have developed bad behaviours. Unfortunately, although the turnover of employees is such a severe problem around the world, there are many studies to investigate this. Still, 
employee turnover has not decreased (Veloulsou, 2004). The rise of voluntary turnover from year to year puts the company into a challenging situation in maintaining the workforce and coordinating activities in the company. The problem of the insufficient workforce will limit the growth of a business and burden the existing staff with extra responsibilities, which will lead to job stress (Harper, 2016).

Turnover intention is a measurement of whether a business' or organization's employees plan to leave their positions. Curtis (2016) explains that 'Turnover is the process through which staff leave a business or organization and that company or organization replaces them. In recent years, turnover has become a culture or trend in almost all industries. High turnover has become a crucial and problematic issue that concerns all companies, as it will affect the company's overall profitability (Mohammad et al., 2014). Previous studies on turnover found that many organizations face challenges in hiring and retaining talent in their organisation because of increasing demand and better opportunities that lead employees to decide to relocate to another.

High turnover is an unfavourable situation that will result in increased costs in terms of recruitment, training, and development as well as benefits and compensation. When an employee leaves the organization, the management has to incur additional expenses by recruiting new staff, designing a new salary package, and providing a training course. Eventually, it will have a negative impact on the financial organization's performance in the market in terms of profit margin. (Mohammad et al., 2014). The study will help human resources managers to better align their employee retention programme instead of focusing only on salary increment, thus improving the financial companies' productivity and overall performance.

\section{Background of the Study}

Apart from the banking sector, nonbanking financial companies provide most of the job opportunities to young employees. Employees from those companies are always working under pressure of unrealistic deadlines and their profit targets. So that the study has focused on finding out the factors that affect the intention to leave. When a few employees leave the company, it will lead to high turnover rates and that cause low productivity and high costs. Therefore, companies must aim to provide a good working environment for employees to get a low turnover rate. For that, they should focus on all the variables that intentionally or unintentionally affect the turnover intention in employees.

According to Banki (2016), financial intermediaries are the firms whose primary business is to provide customers with financial products and services that cannot be obtained more efficiently by transacting directly in the securities market. Engaging more women in to the workforce is the main reason for the increased turnover rates in the nonbanking sector. In 2001, an Insurance company experienced some problem with employee turnover. The staff turnover rate shot up to $48 \%$ subsequently sought to bring satisfaction to beloved employees. According to the Central Bank of Sri Lanka, there are 44 licensed finance companies mainly in Sri Lanka as at 31st of March 2018. Annual 
reports in the financial industry showed that the turnover ratio fluctuates from $8 \%$ to $25 \%$. This Study has selected all the non-managerial employees who are working in selected financial companies in selected towns with special reference to Colombo district Sri Lanka.

\section{Statement of the Problem}

Employee turnover is a serious issue, especially in the field of human resource management. In Sri Lankan context employee turnover is cost making situation to private and public sector organizations (Storey, 2001). Thus, it will negatively affect the organization in terms of overall expenditure and the abilities to distribute the minimum required service.

In the case of turnover, the organization should set up all these variables, and that will cause a huge cost to an organization. The cost of employee turnover for-profit organizations has been estimated to be up to $150 \%$ of the employees' remuneration package (Hossin, 2017). According to the labour demand survey report, 2017 female resignation is $56.6 \%$ and the male resignations $43.4 \%$ in Sri Lanka.

Most of the previous studies were carried out in banking sector, logistic sector, garment sector, ICT industry sector but less studies were concerned the financial service sector employees. Therefore, the study was aimed to find out the factors affecting employee turnover intention in the financial service industry by using selected financial companies in Sri Lanka. This has been mostly covered 3 central leading financial company employees with special reference to Colombo district. There were evidence proved that employee turnover rate in financial service companies was comparatively high.

\section{Factors affecting employee turnover intention among non- managerial employees}

The study aimed to identify the factors that lead to non-managerial level Employees' intention to leave at one of the leading selected finance companies in Sri Lanka. The study further examined the dimension on the employees' turnover intention, which was a controllable and uncontrollable force. Turnover intention, salary benefit, organizational culture, job satisfaction and supervisor support were the five variables of the study.

Remuneration is negatively associated with turnover intention in most industry. Workers are leaving their organization repulses by better salary at other organization. The turnover intention is high for those who are value the salary package or remuneration package (Rahman, 2012).

Person-organization culture fit enables the employee to get up immediately to fit with the environment and the culture. According to Porter and Steers (1973), and if the employees are positively matched to the organization culture, the more employees are making a valuable contribution to the organization rather than leave the organization. Furthermore, when an employee shows a high level of commitment, it reflects the employee is more likely to stay in the organization.

Job satisfaction is an essential factor that directly or indirectly has an influence on employee turnover intention. Employees who are dissatisfied create many issues or problems for their instructions instead 
of solving its issue or problems. Unhappy employees generate hazardous problems or issue for the organization rather than using their energy for the accomplishment of its goals and objectives. If dissatisfied employees persisted in the organization may involve in counter-productive behaviours such as poor service, theft, sabotage of equipment and destructive rumours (Steers, 1981). It was also reported that in the literature when employees are dissatisfied, they show physical disturbances such as depression, lassitude, tension, sleeplessness and apprehension. Due to these problems, employees' dissatisfaction gives rise to a high level of turnover intention, which ultimately leads to actual turnover (Price, 1986).

The perceptions and attitudes that employees develop toward their supervisors can translate into perceptions and attitudes that are directed at the organization. Actions taken by agents of the organization, such as supervisors, are seen by employees as indicators of the intentions of the larger employing organization, which is why work characteristics, such as supervisor support, are more closely tied to the turnover intention of employees (Khatri, 2008).

\section{Research Questions}

The study considers the following research questions.

- What is the relationship between salary benefit and turnover intention in financial service industry employees in Sri Lanka?
- What is the relationship between organizational culture and turnover intention in financial service industry employees in Sri Lanka?

- What is the relationship between Job Satisfaction and turnover intention in financial service industry employees in Sri Lanka?

- What is the relationship between supervisor support and the employee turnover intention in financial service industry employees in Sri Lanka?

\section{Research Objectives}

Based on the research problem, five objectives were developed for the study, as mentioned below:

- To examine the relationship between salary benefit and the employee turnover intention in financial service industry employees in Colombo district, Sri Lanka.

- To examine the relationship between organizational culture and the employee turnover intention in financial companies in Colombo district, Sri Lanka.

- To identify the relationship between job satisfaction and the employee turnover intention in financial companies in Colombo district of Sri Lanka.

- $\quad$ To identify the relationship between supervisor support and the employee turnover intention in financial companies in Colombo district. 


\section{Literature Review}

Employee turnover can be defined as the rate at which employees leave a workforce and are replaced. Turnover intention can be classified into unpreventable turnover, desirable turnover and undesirable turnover. The unpreventable turnover is due to the illness, family issue or retirement. Moreover, the desirable turnover is due to the employee's incompetence. Finally, for undesirable turnover would include competent and qualified employees leaving due to such organizational issues as lack of supervision, poor support and role conflict. These issues need to be addressed because they are directly affected by client service quality and organizational effectiveness (She, 2013).

Employee turnover can be divided in to involuntary or voluntary. Voluntary turnover occurs when an employee wants to leave and eventually decides to leave the organization with various causes. It is likely that employee accepted a position, which has a better treatment, whether physical or spiritual with a different company. The best predictor of whether an employee will leave the organization is based on turnover intention of the employees (Shukur, 2015) According to the Labour Demand Survey Report 2017 female resignation is $56.6 \%$ and the male resignations $43.4 \%$ in Sri Lanka. Young employees mostly change jobs when better opportunities come up; especially, for a better job or to go back to education with seasonal work, shift from temporary to a more stable job or because they were not happy with previous job.

Studies have identified several variables that influence the turnover intention of employees. Variables such as salary and other benefits, organizational culture, job satisfaction, and supervisor support affected the turnover intention of employees. Mendis (2017) suggest that salary is basic requirements with the employee; they look for the labour pay remuneration. It means the salary is always a decisive role for most employees. 'Pay' means the salary of employees, which is given for their Service. Employee turnover is influenced by pay. Also mentioned that high salaries are not important, but "good" and "fair" salaries indicate a strong correlation with the intention to remain, signifying that if the compensation is competitive, financial rewards are not the primary factor in retention.

Despite all this, it still does not deny the major effect of salary to employee satisfaction. Maslow hierarchy of needs theory indicates that human have five levels of needs: physiological needs, safety needs, belonging needs, esteem needs and self-actualization needs. Stand in the breach is physiological, thus paying directly influence to physiological needs of the employee.

Kim (2010) supported this testimonial, which signifies that the actual level of pay is less important than feelings about pay raises and the process used to manage them and stated that there is a linear relationship among fringe benefits and turnover intention. Authors recommended having monitory and nonmonitory incentive schemes in place to reduce the high turnover since the high frequency of turnover has a significant impact on overall company achievements. Monitory and nonmonitory incentives enhance employee retention and employee commitment. 
Therefore, salary benefit influenced the turnover intention of employees.

Organizational culture acts as a system of social control and influence employees' attitudes and behaviour through the values and beliefs operating in an organization. Thus, the employee's satisfaction, commitment and turnover intention had influenced by the organizational culture. According to Ramesh (2012), he conducted a study on Turnover Intention in Fast Food Industry: Employees' Fit to the Organizational Culture and Important of their Commitment. It is found that organizational culture had an impact on turnover intention.

Lee (2015) defined job satisfaction as a positive feeling consequence from the assessment of an Individuals' job. Many factors are related to job satisfaction, for instance, social relationships, job analysis, employee training, desires and needs, recruitment and selection, orientation, working conditions, development and quality of management. Lambert (1990) stated that turnover could be forecasted by using full measures of the level of job satisfaction. Therefore, increasing level of job satisfaction is strongly correlated with a low rate of turnover. Furthermore, many academic researchers proved that the association between turnover and level of job satisfaction is moderated by turnover intentions.

Maertz et al. (2007) found in their study that the effect of perceived organizational support and perceived supervisor support on employee turnover, there is a strong negative relationship between organizational and supervisor support and employee turnover intention. They concluded that both organizational and supervisor supports are quite valuable implication in turnover management. Therefore, the supervisor should be responsible for maintaining a supportive work environment to build constructive relationships with employees. Such action will eventually help to increase retaining employees within the organization. As supervisors act as agent of the organization, employee who receive better support from his superior and favourable treatments from the organization, they reciprocate by retaining in the organization and it has psychological contact, employee tend to perceive employer by fulfilling its obligations. Xiangping $\mathrm{Wu}$ (2012) investigated the factors affecting employee turnover intention based on the retail industry in Bangkok, Thailand. According to the study, job satisfaction and organizational commitment, and there had both a direct and indirect effect on employee turnover intention. In addition, their study indicated that the effect of perceived organizational support and perceived supervisor support on employee turnover; there is a strong negative relationship between organizational and supervisor support and employee turnover intention. They concluded that both organizational and supervisor supports are quite valuable implication in turnover management. Therefore, the supervisor should be responsible for maintaining a supportive work environment to build constructive relationships with employees. Such action will eventually help to increase retaining employees within the organization. 


\section{Conceptual Framework}

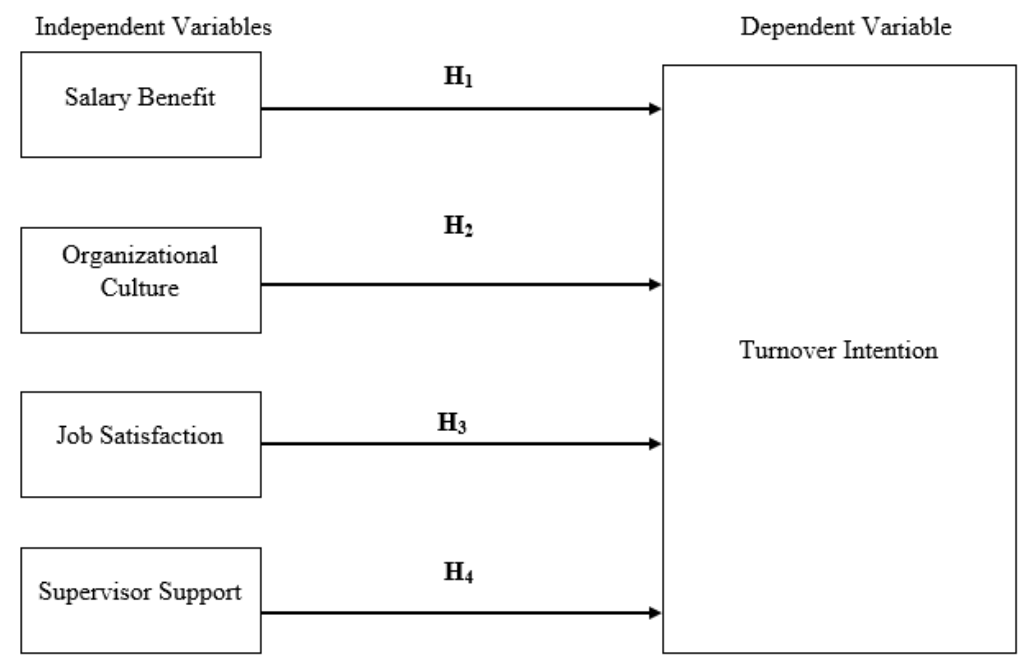

Figure 01: Conceptual Framework Source: Authors, 2019

\section{Hypotheses}

Following hypotheses were advanced in the study to be tested.

$\mathbf{H}_{1}$ : There is a relationship between salary benefit to the employee turnover intention in financial companies in Colombo district.

H2: There is a relationship between organizational culture and the employee turnover intention financial companies in Colombo district.

$\mathbf{H}_{3}$ : There is a relationship between job satisfaction and the employee turnover intention financial companies in Colombo district.

H4: There is a relationship between supervisor support and the employee turnover intention financial companies in Colombo district.

\section{Research Methodology}

This study was categorized as casual research. Casual research enables the researchers to identify the cause-andeffect relationship so that the study can be conducted more effectively, and the result will be more reliable. As a quantitative study, the conclusion is made from that result of the questionnaires distributed to our respondents. The questionnaire included demographic data of the respondent such as gender, age group, educational level as the personal information apart from that it included working experience and employee turnover rate as per knowledge by the respondent. Data collection was done through the standard questionnaires and online system by using a Google form system.

The instruments are tested by doing pilot test and running the reliability test under 
Cronbach alpha for the definite the reliability of the questionnaire and also tested the missing values, outliers, normality, and linearity, as descriptive data analysis. Descriptive analysis, correlation regression analysis using as an objective-based data analysis to evaluating the relationship between dependent and independent variables.

The population of the study is all the Non-managerial employees who are working in all financial companies in Sri Lanka. Therefore, for the research purposes, the study population is selected as all the non- managerial employees who are working in the selected financial companies with special reference to Colombo district. The sample of the study was 150 non-managerial employees who are working in those financial companies located in Colombo district. The sample represented $50 \%$ of the total population.

Apart from that, the researcher selected a simple random sampling method for this study because of the equal and independent chance. Other than that, it is very simple, inexpensive and fast method. Structured questionnaires distributed to respondents. 150 questionnaires were distributed, and 119 were received.

The secondary data was collected from journals, reports, internets, and referent books. Both academic and professional articles are dependable and vital and that enables us to obtain relevant information.
All these journal articles were essential and helpful for the study as they provided a complete description of the purpose of this study, the methods used, and the results of the research.

This research presented a quantitative study with the purpose of quantifying the association between the independent and dependent variables. In order to test the reliability, the study has considered the Cronbach's Alpha value. The data collected with regard to the variables plotted in a scatter diagram, which was helpful in identifying the level of correlation between two dimensions. SPSS Software package (version 23) was applied for the analysis of the data, using statistical tools such as descriptive statistics, the Pearson's correlation, multiple regression and ANOVA. Further regression analysis, coefficient of correlation and correlation of determination calculated.

\section{Analysis and Results}

The measurement of the validity and reliability of the questionnaire is very crucial in the process of data collection. This provides accurate data for the researcher to carry out a successful data analysis and emerge to a valid conclusion. If the questionnaire is not capable of demonstrating the intended, data for the research it fails to achieve the objectives. Therefore, the researcher has carried out a pilot test with 10 participants and has abled to conclude the following insights. 
Table 01: Reliability of Variables (Cronbach's Alpha table)

\begin{tabular}{|l|c|c|}
\hline \multicolumn{1}{|c|}{ Variable/statement } & $\begin{array}{c}\text { No of } \\
\text { items }\end{array}$ & $\begin{array}{c}\text { Cronbach's } \\
\text { alpha }\end{array}$ \\
\hline Salary and the other benefit (Statement 1) & 5 & 0.778 \\
\hline Organizational culture (Statement 2) & 7 & 0.696 \\
\hline Job satisfaction (Statement 3) & 5 & 0.753 \\
\hline Supervisor support (Statement 4) & 5 & 0.676 \\
\hline Employee turnover intention (DV) & 3 & 0.611 \\
\hline
\end{tabular}

Source: Analysed Data, 2019

By considering, the accuracy of the variables of the study has used Cronbach's alpha method. As shown in Table 1, all Cronbach's alpha values were in-between 0.6 to 0.7 for all constructs indicating sufficient internal

Table 02: Case-Processing Summary consistency of the items in the scale. All the independent variables supported the dependent variable of the study. Therefore, the review was reliable as per the statistics.

\begin{tabular}{|l|c|c|c|c|c|c|}
\hline \multirow{2}{*}{} & \multicolumn{3}{|c|}{ Cases } \\
\cline { 2 - 8 } & \multicolumn{2}{|c|}{ Valid } & \multicolumn{2}{c|}{ Missing } & \multicolumn{2}{c|}{ Total } \\
\cline { 2 - 8 } & N & Percent & N & Percent & N & Percent \\
\hline Salary benefit & 119 & $100.0 \%$ & 0 & $0.0 \%$ & 119 & $100.0 \%$ \\
Organizational culture & 119 & $100.0 \%$ & 0 & $0.0 \%$ & 119 & $100.0 \%$ \\
Job satisfaction & 119 & $100.0 \%$ & 0 & $0.0 \%$ & 119 & $100.0 \%$ \\
Supervisor support & 119 & $100.0 \%$ & 0 & $0.0 \%$ & 119 & $100.0 \%$ \\
Turnover intention & 119 & $100.0 \%$ & 0 & $0.0 \%$ & 119 & $100.0 \%$ \\
\hline
\end{tabular}

Source: Analyzed Data, 2019

The researcher has tested missing values of the study according to table 02 , and there are no missing values to find in the data set. The researcher has tested the normality of each variable, and the variable wise results are shown below. 
Table 03: Normality of Turnover Intention

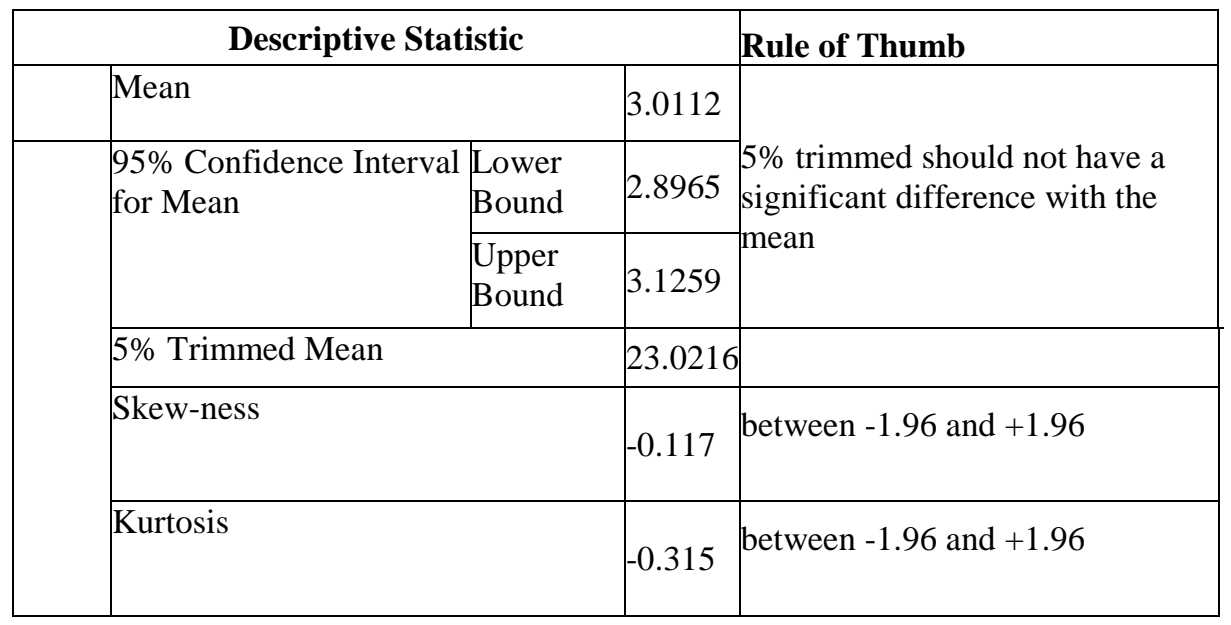

Source: Analyzed Data, 2019

The 5\% trimmed mean no significant difference with the mean where it supports the normality distribution of the data set for the dependent variable. The 0.117 Skew-ness depicts that the symmetric distribution is normal as it closer to " $0 "$ and this is negatively skewed. Under Kurtosis, the data set is with thin the normal distribution but demonstrates a lighter distribution as its negative away from " 0 ". The data set of the dependent variable has an overall normal distribution according to the above indicators.

\section{Table 04: Normality of Salary benefit}

\begin{tabular}{|l|l|l|l|l|}
\hline \multicolumn{3}{|c|}{ Descriptive Statistic } & Rule of Thumb \\
\hline \multicolumn{2}{|c|}{ Mean } & 1.4891 & \\
\hline & $\begin{array}{l}95 \% \text { Confidence } \\
\text { Interval for Mean }\end{array}$ & $\begin{array}{l}\text { Lower } \\
\text { Bound }\end{array}$ & 1.443 & $\begin{array}{l}5 \% \text { trimmed should not have a } \\
\text { significant difference with the } \\
\text { mean }\end{array}$ \\
\cline { 2 - 4 } & $\begin{array}{l}\text { Upper } \\
\text { Bound }\end{array}$ & 1.5338 & \\
\cline { 2 - 4 } $5 \%$ Trimmed Mean & 1.448 & between -1.96 and +1.96 \\
\cline { 2 - 4 } & Skew-ness & 0.252 & between -1.96 and +1.96 \\
\cline { 2 - 3 } & Kurtosis & -0.180 & \\
\hline
\end{tabular}

Source: Analyzed Data, 2019

The 5\% trimmed mean demonstrates no proving the normality in the distribution significant difference with the mean of the data set for salary benefit. 
Skewness is closer to "0" showing a set of salary benefit demonstrates a better favourable distribution of data with a Normal distribution of the data set.

positively skewed illustration. The data

Table 05: Normality of Supervisor Support

\begin{tabular}{|c|c|c|c|}
\hline \multicolumn{3}{|c|}{ Descriptive Statistic } & Rule of Thumb \\
\hline Mean & & 3.0655 & \multirow{3}{*}{$\begin{array}{c}5 \% \text { trimmed should not have a } \\
\text { significant difference with the } \\
\text { mean }\end{array}$} \\
\hline \multirow{2}{*}{$\begin{array}{l}95 \% \text { Confidence } \\
\text { Interval for Mean }\end{array}$} & $\begin{array}{l}\text { Lower } \\
\text { Bound }\end{array}$ & 2.9477 & \\
\hline & $\begin{array}{l}\text { Upper } \\
\text { Bound }\end{array}$ & 3.1834 & \\
\hline \multicolumn{2}{|c|}{$5 \%$ Trimmed Mean } & 3.0456 & \\
\hline \multicolumn{2}{|c|}{ Skew-ness } & 0.175 & between -1.96 and +1.96 \\
\hline \multicolumn{2}{|l|}{ Kurtosis } & -0.435 & between -1.96 and +1.96 \\
\hline
\end{tabular}

Source: Analyzed Data, 2019

The 5\% trimmed mean demonstrates no significant difference with the mean proving the normality in the distribution of the data set for supervisor support. Skew-ness is closer to " 0 " demonstrating a favourable distribution of data with a positively skewed illustration. The data set of supervisor support demonstrates a better normal distribution of the data set.

Table 06: Normality of Job Satisfaction

\begin{tabular}{|c|c|c|c|}
\hline \multicolumn{3}{|c|}{ Descriptive Statistic } & Rule of Thumb \\
\hline \multicolumn{2}{|c|}{ Mean } & 2.2850 & \multirow{3}{*}{$\begin{array}{c}5 \% \text { trimmed should } \\
\text { not have a significant } \\
\text { difference with the } \\
\text { mean }\end{array}$} \\
\hline \multirow{2}{*}{$\begin{array}{l}\text { 95\% Confidence Interval for } \\
\text { Mean }\end{array}$} & $\begin{array}{l}\text { Lower } \\
\text { Bound }\end{array}$ & 2.1922 & \\
\hline & $\begin{array}{l}\text { Upper } \\
\text { Bound }\end{array}$ & 2.3778 & \\
\hline \multicolumn{2}{|l|}{$5 \%$ Trimmed Mean } & 2.2870 & \\
\hline \multicolumn{2}{|l|}{ Skew-ness } & -.083 & $\begin{array}{l}\text { between }-1.96 \text { and } \\
+1.96\end{array}$ \\
\hline \multicolumn{2}{|l|}{ Kurtosis } & -.763 & $\begin{array}{l}\text { between }-1.96 \text { and } \\
+1.96\end{array}$ \\
\hline
\end{tabular}

Source: Analyzed Data, 2019 
The 5\% trimmed mean no significant difference with the mean where it supports the normality distribution of the data set for the dependent variable. The -0.83 Skew-ness depicts that the symmetric distribution is normal as it closer to " 0 " and this is negatively skewed under Kurtosis, the data set is with thin the normal distribution but demonstrates a lighter distribution as it is negative away from " 0 ". The data set of job satisfaction has an overall normal distribution according to the above indicators.

Table 07: Normality of Organizational Culture

\begin{tabular}{|c|c|c|c|}
\hline \multicolumn{3}{|c|}{ Descriptive Statistic } & Rule of Thumb \\
\hline \multicolumn{2}{|c|}{ Mean } & 2.7286 & \multirow{4}{*}{$\begin{array}{l}5 \% \text { trimmed should not have a } \\
\text { significant difference with the } \\
\text { mean }\end{array}$} \\
\hline \multirow{2}{*}{$\begin{array}{l}95 \% \\
\text { Confidence } \\
\text { Interval for } \\
\text { Mean }\end{array}$} & $\begin{array}{l}\text { Lower } \\
\text { Bound }\end{array}$ & 2.6385 & \\
\hline & $\begin{array}{l}\text { Upper } \\
\text { Bound }\end{array}$ & 2.8186 & \\
\hline \multicolumn{2}{|c|}{$5 \%$ Trimmed Mean } & & \\
\hline \multicolumn{2}{|c|}{ Skew-ness } & -.079 & between -1.96 and +1.96 \\
\hline \multicolumn{2}{|c|}{ Kurtosis } & .148 & between -1.96 and +1.96 \\
\hline
\end{tabular}

Source: Analyzed Data, 2019

The 5\% trimmed mean demonstrate no significant difference with the mean where it supports the normality distribution of the data set for the dependent variable. The -0.79 Skewness depicts that the symmetric distribution is normal as it closer to " 0 " and this is negatively skewed. Under Kurtosis, the data set is within the normal distribution but demonstrates a lighter distribution as its negative away from " 0 ". The data set of organizational culture has an acceptable normal distribution. 
Table 08: Correlation Coefficient of Variables

\begin{tabular}{|l|l|l|l|l|l|}
\hline & $\begin{array}{l}\text { Salary } \\
\text { Benefit }\end{array}$ & $\begin{array}{l}\text { Organizational } \\
\text { Culture }\end{array}$ & $\begin{array}{l}\text { Job } \\
\text { Satisfaction }\end{array}$ & $\begin{array}{l}\text { Supervisor } \\
\text { Support }\end{array}$ & $\begin{array}{l}\text { Turnover } \\
\text { Intention }\end{array}$ \\
\hline Salary Benefit & 1 & & & & \\
\hline $\begin{array}{l}\text { Organizational } \\
\text { Culture }\end{array}$ & -0.044 & 1 & & & \\
\hline Job Satisfaction & -0.051 & $-0.334^{* *}$ & 1 & & \\
\hline $\begin{array}{l}\text { Supervisor } \\
\text { Support }\end{array}$ & -0.045 & $-0.324^{* *}$ & $-0.542^{* *}$ & 1 & \\
\hline $\begin{array}{l}\text { Turnover } \\
\text { Intention }\end{array}$ & -0.054 & $-0.344^{* *}$ & $-0.582^{* *}$ & $-0.548^{* *}$ & 1 \\
\hline
\end{tabular}

**Correlation is significant at the 0.01 level (2-tailed)

Source: Analyzed Data, 2019

Accordingly, Salary and the other benefits (SOB) states a value of negative -0.54 that shows the SOB has a negative relationship with the (Employee turnover intention). However, under the relationship with turnover intention and SOB is not significant. It is because the p-value 0.281 is higher than the alpha value of 0.05 .The Organizational Culture (OC) demonstrates a negative 0.344 , and there is a significant relationship with the dependent variable of employee turnover intention.

There is a negative relationship between job satisfaction and turnover intention because of the negative value for the correlation coefficient. Job Satisfaction Shows -0.582 negative \& significant relationship with the dependent variable of employee turnover intention. It is because it has achieved the $\mathrm{p}$-value 0.000 (p value $<0.01$ ).

There is -0.548 negative relationship between supervisor support and turnover intention because of the negative value for the correlation coefficient; it means supervisor support is high employee turnover intention will be low. The relationship between supervisor support and turnover intention is significant. It is because it has achieved the p-value 0.000 ( $\mathrm{p}$ value $<0.01$ ). 
Table 09: Model Summary

Model Summary ${ }^{b}$

\begin{tabular}{|c|c|c|c|c|}
\hline Model & $\mathrm{R}$ & $\mathrm{R}$ Square & $\begin{array}{c}\text { Adjusted R } \\
\text { Square }\end{array}$ & $\begin{array}{c}\text { Std. Error of } \\
\text { Estimate }\end{array}$ \\
\hline 1 & $.641^{\mathrm{a}}$ & .411 & .390 & .49337 \\
\hline
\end{tabular}

a. Predictors: (Constant), supervisor support, salary benefit, organizational culture, job satisfaction

b. Dependent Variable: turnover intention

Source: Analyzed Data, 2019

Multiple correlation " $\mathrm{R}$ " was 0.641 . This says that there was a moderate positive linear relationship between the independent variables and employee turnover intention. R-square is 0.411 . In this study, the independent variables can explain $41.1 \%$ of the variations in the dependent variable. However, there is still 58.9\% (100\%-41.1\%) which cannot be demonstrated in this study. Other than that, there are other additional variables that are important in explaining turnover intention that has not been considered in this study.

Table 10: ANOVA

\begin{tabular}{|c|c|c|c|c|c|c|}
\hline \multicolumn{2}{|c|}{ Model } & $\begin{array}{c}\text { Sum of } \\
\text { Squares }\end{array}$ & df & $\begin{array}{c}\text { Mean } \\
\text { Square }\end{array}$ & F & Sig. \\
\hline \multirow{3}{*}{1} & Regression & 19.347 & 4 & 4.837 & 19.871 & $.000^{\mathrm{b}}$ \\
\cline { 2 - 8 } & Residual & 27.749 & 114 & .243 & & \\
\cline { 2 - 8 } & Total & 47.096 & 118 & & & \\
\hline
\end{tabular}

a. Dependent Variable: turnover intention

b. Predictors: (Constant), supervisor support, salary benefit, organizational culture, job satisfaction

Source: Analyzed Data, 2019

According to the table, this model has 0.00 values for sig value of the ANOVA table. Since it is below than the significant level (0.05), the study can decide that the overall model is fit. In other hands, it can be defined that Salary and the other benefits (SOB), organizational Culture (OC), Job
Satisfaction (JS) and Supervisor Support (SS) can count for variance in Employee Turnover Intention (DV). 
Table 11 :Coefficients of Independent Variables

Coefficients $^{\mathrm{a}}$

\begin{tabular}{|l|c|c|c|c|c|}
\hline \multirow{2}{*}{ Model } & \multicolumn{2}{|c|}{$\begin{array}{c}\text { Unstandardized } \\
\text { Coefficients }\end{array}$} & $\begin{array}{c}\text { Standardized } \\
\text { Coefficients }\end{array}$ & \multirow{2}{*}{ sig } \\
\cline { 2 - 5 } & $\mathrm{B}$ & Std Error & Beta & 2.483 & .014 \\
\hline \multicolumn{1}{|c|}{1 (Constant) } & 1.000 & .403 & & -1.063 & .290 \\
$\begin{array}{l}\text { Mean Work } \\
\text { Environment }\end{array}$ & -.197 & .186 & -.077 & -1.763 & .081 \\
$\begin{array}{l}\text { Mean Leadership } \\
\text { Style }\end{array}$ & -.178 & .101 & -.137 & & \\
$\begin{array}{l}\text { Mean Employee } \\
\text { Benefits }\end{array}$ & -.482 & .118 & -.390 & -4.084 & .000 \\
$\begin{array}{l}\text { Mean Employee } \\
\text { Wellbeing }\end{array}$ & -.236 & .095 & -.243 & -2.486 & .014 \\
\hline
\end{tabular}

a. Dependent Variable: turnover intention

Source: Analyzed Data, 2019

Based on the table, the results show that job satisfaction is significant to predict the dependent variable (turnover intention) for this study. $(\mathrm{p}<0.005)$. Supervisor support is also significant to predict the dependent variable (turnover intention) for this study. ( $\mathrm{p}<0.005)$. Besides that, Salary and the other benefits (SOB) \& Organizational Culture (OC) were not significant to predict the dependent variable (turnover intention) for this study. This is because p-value for SOB and OC is 0.290 and 0.081 respectively, which is higher than the alpha value of 0.05 . Job satisfaction is the predictor variable that contributes the highest variation of the dependent variable (turnover intention) because Beta value (under standardized coefficient) for this predictor variable is the highest (0.390) if compare to other predictor variables (salary and the other benefits, organizational culture and the supervisor support. This means Job satisfaction is the strongest unique contribution to explain the variation in the dependent variable (turnover intention), when the variance explained by all other predictor variables in the model is controlled for.

Standardized Coefficients B value of the path model for Salary and the other benefits (SOB) is -0.077 . Which means there is a negative relationship between employee turnover intentions (DV), the Salary, and the other benefits (IV). However, according to the above table, there is no significant relationship between turnover intention and the salary 
and the other benefits (SOB). Because of that significant relationship among the above variables. So that the study explained Salary and the other benefits are not significantly affects to determine the employee turnover intention of the particular industry.

Standardized coefficients B value of the path model for organizational culture (OC) is -0.137 , which means 0.137 of Employee turnover Intention will be increased (negative) when the $\mathrm{OC}$ is changed by one unit. However, there is no significant relationship between Organizational Culture and the employee turnover intention of that particular sample sector. Because of that table shows that significant level of the above variable is 0.081 , which is higher than the standardized p-value. So Organizational Culture is not sensitive to the employee turnover intention of the financial service industry.

Standardized coefficients B value of the path model for Job satisfaction (JS) is 0.390, which means -0.390 of Employee turnover intention will be increased (negative) when the JS is changed by one unit with 0.000 of the statistical significance level.

Standardized coefficients B value of the path model for Supervisor Support (SS) is -0.243 , which means 0.243 of Employee turnover Intention will be decreased (Negative) when the OC is changed by one unit with 0.014 of higher significant level.

\section{Hypotheses Testing - Results}

Table 12: Hypotheses Testing

\begin{tabular}{|c|l|c|}
\hline $\mathbf{H}_{1}$ & $\begin{array}{l}\text { There is a relationship between salary benefit and } \\
\text { employee turnover intention. }\end{array}$ & Rejected \\
\hline $\mathbf{H}_{2}$ & $\begin{array}{l}\text { There is a relationship between organizational } \\
\text { culture and employee turnover intention. }\end{array}$ & Rejected \\
\hline $\mathbf{H}_{3}$ & $\begin{array}{l}\text { There is a relationship between job satisfaction and } \\
\text { employee turnover intention. }\end{array}$ & Accepted \\
\hline $\mathbf{H}_{4}$ & $\begin{array}{l}\text { There is a relationship between supervisor support } \\
\text { and employee turnover intention. }\end{array}$ \\
\hline
\end{tabular}

Source: Researcher, 2019

The table was formulated for which the research hypotheses sought to test. Based on the regression results, the study has tested the hypotheses. After analyzed the research data, the researcher has found that the job satisfaction and supervisor support significantly impact on employee turnover intention; hence, the hypotheses $\mathrm{H}_{3}$ and $\mathrm{H}_{4}$ were accepted. The correlation coefficient between salary and other benefits, organizational culture and employee turnover intention is insignificant so that the hypothesis $\mathrm{H}_{1}$ and $\mathrm{H}_{2}$ were rejected. 


\section{Findings}

The major findings revealed in this study are given below. The correlation coefficients between salary and other benefits, organizational culture and employee turnover intention is insignificant and were indicated a negative relationship. So that the study explained salary and the other benefits were not significantly affected to determine the employee turnover intention of the industry. In addition, the organizational culture is not sensitive to the employee turnover intention of the financial service industry.

Salary and other benefits, organizational culture, job satisfaction and supervisor support influenced negatively on employee turnover intention of the financial service industry but the impact of salary and other benefits and organizational culture was insignificant.

The Beta values of the three independent variables proved that all four of these variables negatively influence the employee turnover intention of the financial service industry.

Regression results showed total model summary, which indicates a moderate correlation between dependent and independent variables. Independent variables of the study were not sufficient to describe the dependent variable. Therefore, other additional variables are important in explaining turnover intention that has not been considered in this study.
According to the ANOVA overall model is significant. Apart from that supervisor support, (SS) and job satisfaction (JS) showed a negative and significant relationship with DV. Therefore, hypotheses $\mathrm{H}_{1}$ and $\mathrm{H}_{2}$ were rejected and $\mathrm{H}_{3}$ and $\mathrm{H}_{4}$ were accepted in this study.

\section{Conclusion}

The purpose of this study was to determine the factors that affect to employee's turnover Intention in the financial service industry. The study has successfully proved that all independent variables have a significant and insignificant relationship with the dependent variable. However, according to the results, job satisfaction and supervisor-subordinate relationship is the main factors, which influence to turnover intention. Therefore, this research provides valid and reliable information for future researchers.

Employee job satisfaction occurs in many ways. Favourable culture training, promotion supervisor-subordinate relationship and compensation package are crucial in determining the turnover intention of an employee. Nowadays, monetary remuneration is not sufficient to satisfy the staff. Especially employees those who are rewarded commission income for their businesses. That was proved in this study also. It could also involve the intangible variables such as supervisor's acknowledgement and recognition of efforts, which can make the staff feel that their existence and contribution to the organization is 
appreciated. Besides, job satisfaction is also one of the major factors in predicting turnover intention. Once, employees satisfied with their current work, they are willing to stay with the organization. Management of the financial service organizations should carefully take into considerations on these factors to effectively control and manage the issue in the turnover intention of the financial service industry.

\section{Implications}

The results obtained from this study provide insight for better understanding between the four independent variables (Salary benefit, organizational culture, job satisfaction, supervisor support) and the dependent variable which was the turnover intention among employee's selected financial companies in Sri Lanka. Companies tend to control employees' turnover due to the significant costs resulted from the loss of the employees. This research provides practical implications that allow the management of those companies to understand their employees better and to consider these independent variables in designing the companies' policies and culture.

Based on the findings, Salary and the other benefits have no strongest impacts to finance company employees' turnover intention. Because of that, the financial companies mostly provided leasing facility-related services to customers. And most of the employees were in this sample are leasing officers. So that they have rewarded commission income for their target achievement so that their turnover intention is not related to their salary and the other benefits. If they make more customers, they will be rewarded more commission income for that. So that we can conclude that salary benefit had not significantly affected by the turnover intention of that particular sample employees.

Organizational culture negatively correlated with turnover intention. But in this study organizational culture was not significantly affected by employee turnover intention with the financial service industry employees. But organizational culture indirectly affected by the job satisfaction of the employees so that the management should maintain the clear, favourable culture and the working environment in the organization to minimize the turnover intention of the employees. Job satisfaction variable is negatively correlated and significantly affected the turnover intension in every industry level employee. The management should be aware of maintaining the employees' job-related interest level by practicing different techniques such as job rotation and job enhancement.

Thus, the result from this research helps the management in planning, designing, and revising the company culture and policies, which in turn increase the job satisfaction level of the employees. Because of increased job satisfaction, the 
turnover intention of the employees can be minimize.

Supervisor support and employee turnover intention are negatively correlated with each other. Those employees who were unable to form a closer relationship with the leader tend to have a higher level of turnover intention as there is no strong emotional attachment to the leader or the immediate superior. On the other hand, those ingroup members have more significant job opportunities and receive a higher level of support from the leader.

Therefore, by understanding the impact of leader-member exchange towards the level of the turnover intention of the employees, managers can minimize the turnover rate of the organization.

\section{Future research prospects}

The researchers are encouraged to enlarge the sample size and set a high population to acquire more reliable and valid results. On the other hand, this study concerned only the questionnaire method to gather the research data. Therefore, future researchers recommended that personal interview and telephone interview can also be done to collect the data. For instance, allowing the researchers giving better and clearer explanations to the respondents and thus permitting greater reliability of the data gathered. Furthermore, future researchers are also suggested to include other factors which are not investigated in this research. This is because there are still other factors that can impact the turnover intention of employees.

\section{References}

Banki, Z. (2016). Determinators of auditors' turnover intenstion in public Audit firms. Imperial Journal of Interdisciplinary Research (IJIR).Vol-2, Issue-2

Curtis, M. (2019 June 19). What Is Turnover Intention? Retrieved from https://smallbusiness.chron.com/turnover-intention-12753.html

Harper, M.N. (2016). Understanding issues in the workplace. Chron.com, 26 October. Retrieved 15 February 2017 from http://smallbusiness.chron.com/understading-issues-workplace-46884.html.

Hossin, K. (2017). Factors Affecting Employee's Turnover Intention in Banking Sector of bangaladesh. ASA University Review, Vol. 11 No. 2, JulyDecember, 2017.

Khatri, P. B. (2008). Human Resource Management. Employee turnover: A bad attitude or Poot management, 11(1), 54-74.

Kim, B. L. (2010). An examination of the nature of the relationship between LeaderMember-Exchange (LMX) and turnover intent at. International Journal of Hospitality Management, 591-597. 
Lambert, S.J. (1990). Processes linking work and family: A critical review and research agenda

Maertz, C.P., Jr, Griffeth, R.W., Campbell, N.S. and Allen, D.G. (2007). The effects of perceived organizational support and perceived supervisor support on employee turnover. Journal of Organizational Behavior, 28: 1059-1075. doi:10.1002/job.472

Mendis, M.V.S. M. M. (2017). The impact of turnover intention in reward system of the employees. International Journal of Scientific \& Technology Research Volume 6, Issue 09, September 2017.

Mohammad, F.N., Chai, L.T., Aun, L.K., \& Migin, M.W. (2014). Emotional intelligence and turnover intention. International Journal of Academic Research, 6(4), 211-220.

Porter, L. \& Steers, R. (1973). Organizational, work, and personal factors in employee turnover and absenteeism. Psychological Bulletin, 80(2), 151-76.

Price, J. M. (1986). Absenteeism and Turnover of Hospital Employees. Greenwich CT JAI.

Rahman, R. B. (2012). A Study on Turnover Intention Trend in Commercial Banks in Penang, Malaysia

Ramesh, E. (2012). A Study on Turnover Intention in Fast Food Industry: Employees' Fit to the Organizational Culture and the Important of their Commitment. International Journal of Academic Research in Business and Social Sciences May 2012, Vol. 2, No. 5.

She, C. K. (2013). Factors that impact turnover intention of employees among some firms. University Tunku Abdul Rahman.

Shukur, G. A. (2015). Job Satisfaction and Employee Turnover Intention: A Case Study of Private Hospital in Erbil. International Journal of Social Sciences \& Educational Studies, ISSN 2409-1294 (Print), September 2015, Vol.2, No.1.

Sri Lanka labor demand survey. (2017, September 30). Battaramulla: Department of Census and Statistics, Ministry of National Policies and Economic Affairs. Retrieved from http://www.statistics.gov.lk/

Steers/, R. \&. (1981). A Model of Voluntary Employee Turnover in Cummings. Research in organizational Behavior, 233-281.

Storey, J. (2001). Introduction: From Personnel Management to Human Resource. London: Thomson Learning.

Tsai, Y. \& Wu, S.- W. (2010). The relationships between organizational citizenship behaviour, job satisfaction and turnover intention. Journal of Clinical Nursing, 19: 3564-3574. doi:10.1111/j.1365-2702.2010.03375.x 
Veloulsou, C. (2004). Consumer Brand Managers' Job Stress, Job satisfaction perceived performance and intention to leave. Journal of Marketing Management.

Xiangping, W. (2012). Factors Influencing Employee Turnover Intention: case of the retail industry Bangkok. University of the Thai Chamber of Commerce. 